\title{
Target volume settings for home mechanical ventilation: great progress or just a gadget?
}

\author{
Wolfram Windisch, Jan Hendrik Storre
}

Home mechanical ventilation (HMV) is a well-established treatment option for patients with chronic hypercapnic respiratory failure, whereby non-invasive positive pressure ventilation (NPPV) serves as the predominant means of HMV delivery. ${ }^{1} 2$ In general, there are two physiologicallydifferent modes of NPPV deliveries, volume-preset NPPV and pressure-preset NPPV. During volume-preset NPPV a fixed inspiratory volume $\left(\mathrm{V}_{\text {insp }}\right)$ is set at the ventilator, while the inspiratory positive airway pressure (IPAP) varies depending on airway resistance. Conversely, $V_{\text {insp }}$ varies during pressure-preset NPPV, while IPAP remains fixed. The advantage of volume-preset NPPV is that $V_{\text {insp, and }}$ hence tidal volume, are relatively stable; however, this can lead to a breath-bybreath variation in IPAP levels that can become a burden for the patient, and the leakages that regularly occur during NPPV are not compensated for. In contrast, the $\mathrm{V}_{\text {insp }}$ that is delivered during pressurepreset NPPV may be unstable due to increased airway resistance; however, given that the variation in IPAP is lower, this is often better tolerated by the patient. In addition, leak compensation is provided by pressure-preset NPPV, as shown by in vitro ${ }^{3}$ and in vivo ${ }^{4}$ studies. In addition, ventilators providing pressurepreset NPPV are cheaper. Thus, pressurepreset NPPV has become the predominant means of delivering HMV. Nevertheless, randomised controlled trials have shown that volume- and pressure-preset NPPV generally have comparable effects on improvements in blood gases, sleep quality and health-related quality of life (HROL), ${ }^{5}{ }^{6}$ although pressure-preset NPPV is reportedly better tolerated due

Department of Pneumology, Cologne-Merheim Hospital, Kliniken der Stadt Köln gGmbH, Witten/Herdecke University Hospital, Germany

Correspondence to Professor Wolfram Windisch, Department of Pneumology, Cologne-Merheim Hospital, Kliniken der Stadt Köln gGmbH, Witten/Herdecke University Hospital, Ostmerheimer Strasse 200, D-51109 Köln, Germany; windischw@kliniken-koeln.de to fewer gastrointestinal side effects. ${ }^{5}$ However, clinicians should always weigh the advantages and disadvantages of the two different approaches on an individual patient basis.

Recently, the so-called hybrid modes have been developed to overcome the disadvantages of volume- and pressurepreset NPPV, respectively. These modes seek to combine the advantages of the two classical modes, that is, the stability of $V_{\text {insp }}$ and the avoidance of cumbersome variations in breath-by-breath IPAP levels. This is achieved by setting a so-called 'target volume'. Here, pressure-preset NPPV is primarily used, but instead of a fixed IPAP, a pressure range with minimal and maximal IPAP values is set at the ventilator. In response to the automatic calculations and adjustments made by the ventilator, IPAP can undergo a smooth transition within a preset range in order to reach the target volume.

The most extensively studied hybrid mode is the Average Volume Assured Pressure Support (AVAPS) mode. An initial randomised-controlled cross-over trial suggested that the addition of AVAPS to pressure-preset NPPV resulted in better control of nocturnal ventilation compared with pure pressure-preset NPPV in patients with obesity hypoventilation syndrome (OHS). ${ }^{7}$ However, both HROL, as assessed by the Severe Respiratory Insufficiency (SRI) questionnaire, ${ }^{89}$ and sleep quality, as measured by polysomnography, showed similar improvements under each of the two modes. Subsequent trials that primarily included OHS and chronic obstructive pulmonary disease (COPD) patients showed an overall comparable outcome, although nocturnal hypoventilation was better controlled in some trials (table 1). However, in one study polysomnographic sleep quality was shown to be reduced during AVAPS compared with pure pressure-preset NPPV, ${ }^{10}$ probably as a result of considerably high target volume settings (table 1). However, observational periods were rather short in the previous trials, and in some cases patients were already familiar with pressure-preset NPPV prior to randomisation, thus indicating a selection bias. Therefore, the evidence for target volume setting remains inconclusive, and it is yet to be established whether these hybrid modes of ventilation have benefits that are clear and consistent enough to warrant official recommendations.

Murphy and colleagues randomly allocated 50 NPPV-naive patients with severe OHS (body mass index $50 \pm 7 \mathrm{~kg} / \mathrm{m}^{2}$ ) either to pure pressure-preset NPPV using pressure support ventilation or to AVAPS mode, with 46 patients completing the trial. ${ }^{14}$ After 3 months of treatment, daytime arterial partial pressure of carbon dioxide (primary outcome) improved comparably in both groups by a mean $0.6 \mathrm{kPa}$. In addition, improvements in HROL-again measured with the highly specific $\mathrm{SRI}^{8}{ }^{9}$-also showed a similar improvement in both groups, while both treatment strategies resulted in equivalent degrees of weight loss (table 1); therefore, AVAPS was not advantageous. This study significantly adds to the current body of knowledge about target volume setting used for HMV for the following reasons.

First, it is the largest randomised controlled trial investigating HMV with target volume settings, and second, the observational period is the longest implemented to date (table 1). Third, and most importantly, ventilator settings were individually adjusted according to a predefined protocol that included a nocturnal assessment period aimed at achieving optimal control of nocturnal ventilation. This protocol was a unique aspect of the study and held true for both modes, rather than just for the AVAPS settings. Therefore, patients could be discharged after optimal treatment had been established, with or without AVAPS. As a consequence, target volume settings did not provide any additional benefits compared with pressure-preset NPPV.

In reality, clinicians are regularly confronted with new technical developments for HMV, whereby new modes and features are increasingly provided without any evidence of benefits or even without clear recommendations on how to adjust the settings. Target volume serves as an excellent example: despite the lack of evidence for any actual benefits, many new-generation ventilators provide target volume modes. Confusingly, the nomenclature and algorithms used for IPAP adaptation vary considerably among different types of ventilators and 
Table 1 Clinical studies on target volume during pressure-preset ventilation

\begin{tabular}{|c|c|c|c|c|c|}
\hline Study & Year & Design & Cohort & Target volume setting & Main target volume outcomes* \\
\hline Storre et $a l^{7} \dagger$ & 2006 & 6-week cross-over RCT $(n=10)$ & $\mathrm{OHS} \neq$ & $7 \mathrm{ml} / \mathrm{kg} \mathrm{IBW}(\mathrm{n}=5), 10 \mathrm{ml} / \mathrm{kg}$ IBW $(\mathrm{n}=5)$ & $\begin{array}{l}\text { Greater reduction in nocturnal } \mathrm{PtcCO}_{2} \\
\text { Comparable effect on polysomnog- } \\
\text { raphy } \\
\text { Comparable effect on quality of life }\end{array}$ \\
\hline Janssens et $a l^{10} \dagger$ & 2009 & 1-day cross-over RCT $(n=12)$ & OHS & $7.5 \pm 0.8 \mathrm{ml} / \mathrm{kg}$ body weight & $\begin{array}{l}\text { Greater reduction in nocturnal } \mathrm{PtcCO}_{2} \\
\text { Worse polysomnography }\end{array}$ \\
\hline Ambrogio et $a l^{11} \dagger$ & 2009 & 1-day cross-over RCT $(\mathrm{n}=28$ ) & Mixed $\uparrow$ & $8 \mathrm{ml} / \mathrm{kg} \mathrm{IBW}$ or $110 \%$ of baseline VT & $\begin{array}{l}\text { Comparable effect on polysomnog- } \\
\text { raphy } \\
\text { - Greater nocturnal minute volume }\end{array}$ \\
\hline Crisafulli et $a l^{12} \dagger$ & 2009 & 5-day cross-over RCT $(n=9)$ & COPD & $8 \mathrm{ml} / \mathrm{kg} \mathrm{IBW}$ & $\begin{array}{l}\text { Comparable improvements in morning } \\
\mathrm{PaCO}_{2} \\
\text { Subjective improvement in sleep effi- } \\
\text { ciency }\end{array}$ \\
\hline Oscroft et al ${ }^{13} \S$ & 2010 & 8-week cross-over RCT $(n=24)$ & COPD & $11.0 \pm 3.9 \mathrm{l} / \mathrm{min}$ (minute volume) & $\begin{array}{l}\text { Comparable effects on: } \\
\text { - Daytime blood gases } \\
\text { - Lung function and exercise capacity } \\
\text { - Quality of life } \\
\text { - Nocturnal } \mathrm{PtcCO}_{2}\end{array}$ \\
\hline Murphy et $a l^{14} \dagger$ & 2012 & 3-month RCT $(n=46)$ & $\mathrm{OHS} \neq$ & $\begin{array}{l}\text { Individual adjustments aimed at achieving } \\
\text { control of nocturnal hypoventilation while } \\
\text { abolishing obstructive events }\end{array}$ & $\begin{array}{l}\text { Comparable effects on: } \\
\text { - Daytime } \mathrm{PaCO}_{2} \text { improvements } \\
\text { - Quality of life } \\
\text { - Weight loss } \\
\text { - Comparable improvements in ESS }\end{array}$ \\
\hline
\end{tabular}

${ }^{*}$ Compared with conventional pressure-preset non-invasive positive pressure ventilation (NPPV).

†Mode for target volume: average volume assured pressure support.

$\ddagger$ Patients naive to any form of NPPV.

$\S$ Mode for target volume: intelligent volume assured pressure support.

TPatients already established on pressure-preset NPPV.

COPD, chronic obstructive pulmonary disease; ESS, Epworth Sleepiness Score; IBW, ideal body weight; OHS, obesity hypoventilation syndrome; PaCO ${ }_{2}$, arterial partial pressure of carbon

dioxide; $\mathrm{PtcCO}_{2}$, transcutaneous partial pressure of carbon dioxide; RCT, randomised controlled trial; VT, tidal volume.

manufacturers. In addition, real target volume settings also show considerable variation among different studies (table 1); this is most likely due to the lack in the availability of recommendations for its use. Indeed, the inappropriate use of these settings can even be harmful. Of note, Murphy and colleagues established that a target volume of $10 \mathrm{ml} / \mathrm{kg}$ ideal body weight was the most appropriate for AVAPS in their cohort.

New modes and features like target volume might provide an impression of improved alveolar ventilation control; however, it is important to note that HMV has already been successfully applied for nearly 20 years. ${ }^{1516}$ Indeed, it is obviously the details of the settings rather than the mode of ventilation which seems to matter the most. The new study by Murphy and colleagues teaches us that thoughtful adjustment of ventilator settings according to nocturnal monitoring is essential for proper control of nocturnal hypoventilation, thus relegating the ventilation mode to secondary importance. Clearly, patients may benefit on an individual basis when they are switched from one NPPV mode to another, ${ }^{6}$ and this idea might also be valid for target volume. Therefore, while target volume should not be entirely disregarded, the results of the present and previous trials suggest that target volume setting is generally not recommendable.

Finally, the study by Murphy and colleagues provides another clinically important detail: The authors convincingly showed that patients who received more than $50 \%$ of breaths without triggering (controlled ventilation) had a substantially better outcome compared with patients who received more than $50 \%$ of breaths with triggering (supported ventilation), irrespective of whether AVAPS or pure pressure-preset NPPV was used. Thereby, both daytime and nocturnal gas exchange was improved clearly favoured by controlled NPPV. This resulted in an impressive mean difference of $1.9 \mathrm{~kg} / \mathrm{m}^{2}$ body mass index (reduction) and led to a score difference of 10 points (= improvement) as assessed by the SRI; there was also an improvement in subjective sleepiness. These findings also highlight the importance of measuring HRQL as specifically as possible when assessing specific treatment interventions. The SRI is specifically tailored to patients receiving $\mathrm{HMV}^{8}{ }^{9}$ and the present study shows that this tool is capable of differentiating between different ventilatory approaches. In contrast, there was no difference detected in HROL (SRI) between AVAPS and pure pressure-preset NPPV, not because an insensitive assessment tool was used, but simply because there was no difference present.

Controlled NPPV with high inspiratory pressures has recently been developed for COPD patients and is referred to as highintensity NPPV. ${ }^{17} 18$ This approach was shown to be superior to assisted NPPV with lower pressures (low-intensity NPPV) in terms of controlling nocturnal hypoventilation in chronic hypercapnic COPD patients; moreover, high-intensity NPPV promoted better lung function, and improved both dyspnoea and HROL (again assessed by the SRI). ${ }^{19} 20$ The study by Murphy and colleagues also supports the idea that a controlled form of ventilation is the primary determinant for successful NPPV in OHS patients. However, as this was not the primary aim of the study, further work on this issue is definitely warranted. Nevertheless, we anticipate a paradigm shift towards the use of controlled NPPV being used in favour of assisted or supported NPPV modes for nocturnal HMV. Controlled ventilation, however, can be achieved by all classical modes. In this regard, target 
volume appears to be more of a gadget than a great progressive tool.

Contributors Both authors contributed equally to the article.

\section{Competing interests None.}

Provenance and peer review Commissioned; internally peer reviewed.

Published Online First 15 April 2012

Thorax 2012;67:663-665.

doi:10.1136/thoraxjnl-2012-201679

\section{REFERENCES}

1. Janssens JP, Derivaz $S$, Breitenstein $E$, et al Changing patterns in long-term noninvasive ventilation: a 7-year prospective study in the Geneva Lake area. Chest 2003:123:67-79.

2. Lloyd-Owen SJ, Donaldson GC, Ambrosino N, et al. Patterns of home mechanical ventilation use in Europe: results from the Eurovent survey. Eur Respir $J$ 2005:25:1025-31.

3. Mehta S, McCool FD, Hill NS. Leak compensation in positive pressure ventilators: a lung model study. Eur Respir J 2001;17:259-67.

4. Storre JH, Bohm P, Dreher M, et al. Clinical impact of leak compensation during non-invasive ventilation Respir Med 2009;103:1477-83.

5. Windisch W, Storre JH, Sorichter S, et al. Comparison of volume- and pressure-limited NPPV at night: a prospective randomized cross-over trial. Respir Med 2005:99:52-9.

6. Tuggey JM, Elliott MW. Randomised crossove study of pressure and volume non-invasive ventilation in chest wall deformity. Thorax 2005:60:859-64.

7. Storre $\mathbf{J H}$, Seuthe B, Fiechter $\mathrm{R}$, et al. Average volume-assured pressure support in obesity hypoventilation: a randomized crossover trial. Chest 2006; 130:815-21.

8. Windisch W, Freidel K, Schucher B, et al. The Severe Respiratory Insufficiency (SRI) Questionnaire: a specific measure of health-related quality of life in patients receiving home mechanical ventilation. J Clin Epidemiol 2003:56:752-9.

9. Gosh D, Rzehak P, Elliott MW, et al. Validation of the English severe respiratory insufficiency Questionnaire. Eur Respir J. Published Online First: 19 December 2011. doi: $10.1183 / 09031936.00152411$

10. Janssens JP, Metzger M, Sforza E. Impact of volume targeting on efficacy of bi-level non-invasive ventilation and sleep in obesity-hypoventilation. Respir Med 2009;103:165-72.

11. Ambrogio C, Lowman X, Kuo M, et al. Sleep and non-invasive ventilation in patients with chronic respiratory insufficiency. Intensive Care Med 2009;35:306-13.

12. Crisafulli E, Manni G, Kidonias M, et al. Subjective sleep quality during Average volume assured pressure support (AVAPS) ventilation in patients with hypercapnic COPD: a Physiological Pilot study. Lung 2009;187:299-305.
13. Oscroft NS, Ali M, Gulati A, et al. A randomised crossover trial comparing volume assured and pressure preset noninvasive ventilation in stable hypercapnic COPD. COPD 2010;7:398-403.

14. Murphy P, Davidson AC, Hind M, et al. Volume Targeted versus pressure support non-invasive ventilation in Super-Obese patients with chronic respiratory failure: a randomised controlled trial. Thorax 2012;67:727-34.

15. Leger $\mathbf{P}$, Bedicam JM, Cornette A, et al. Nasal intermittent positive pressure ventilation. Long-term follow-up in patients with severe chronic respiratory insufficiency. Chest 1994;105:100-5.

16. Simonds AK, Elliott MW. Outcome of domiciliary nasal intermittent positive pressure ventilation in restrictive and obstructive disorders. Thorax 1995; 50:604-9.

17. Windisch W, Haenel M, Storre JH, et al. High-intensity non-invasive positive pressure ventilation for stable hypercapnic COPD. Int J Med Sci 2009;6:72-6.

18. Windisch W. Noninvasive positive pressure ventilation in COPD. Breathe 2011:8:114-23.

19. Dreher M, Storre H, Schmoor C, et al. High-intensity versus low-intensity noninvasive ventilation in stable hypercapnic COPD patients: a randomized cross-over trial. Thorax 2010;65:303-8.

20. Dreher M, Ekkernkamp E, Storre JH, et al. Noninvasive ventilation in COPD: impact of inspiratory pressure levels on sleep quality. Chest 2011;140:939-45

\section{Stability of inflammatory phenotypes in asthma}

\section{Ruth H Green, lan Pavord}

While asthma has long been recognised as a heterogeneous disease, recent interest has concentrated on the identification of phenotypes based on the pattern of inflammation in the airways. The application of induced sputum as a non-invasive 'inflammometer' has facilitated this process, resulting in the recognition of apparently distinct 'eosinophilic' and 'non-eosinophilic' phenotypes. The characterisation of patients in this way appears attractive since the response to treatment, particularly with inhaled corticosteroids, has been shown to differ according to the pattern and extent of inflammation. This has contributed to the concept of a 'holy grail' of individualised therapy based on phenotypic expression and a flurry of studies aiming to further

Department of Respiratory Medicine, Glenfield Hospital, Leicester, UK

Correspondence to Dr Ruth H Green, Department of Respiratory Medicine, Glenfield Hospital, Leicester LE3 90P, UK; ruth.green@uhl-tr.nhs.uk explain and refine the phenotypic diversity seen in both adults and children with asthma. A number of questions remain, however, and one important one raised by Fleming et $a l^{1}$ is whether there are differences in the nature and significance of airway inflammation between adults and children with asthma.

Adult studies using induced sputum have consistently identified distinct eosinophilic and non-eosinophilic asthma subgroups. While the use of inhaled corticosteroids, which effectively suppress sputum eosinophilia, is a significant confounder, normal sputum eosinophil counts have been reported in up to $25 \%$ of adult patients with untreated symptomatic asthma ${ }^{2}$ and for over $50 \%$ of adult patients treated with high doses of inhaled corticosteroids. ${ }^{3}$ Simpson and colleagues have suggested that airway inflammation in adult asthma could be further categorised into four inflammatory subtypes, namely, neutrophilic asthma (neutrophils $>61 \%$ ), eosinophilic asthma (eosinophils
$>3 \%$ ), mixed granulocytic asthma (neutrophils and eosinophils both increased) and paucigranulocytic asthma where neutrophils and eosinophils are both within the normal range. ${ }^{4}$ In populations of patients with stable adult asthma, the majority treated with inhaled corticosteroids, paucigranulocytic asthma appeared to be the most common inflammatory phenotype followed by neutrophilic inflammation. ${ }^{5}$ Non-eosinophilic asthma has also been reported in children with asthma. ${ }^{7}$ Paucigranulocytic asthma was the predominant finding in children with stable asthma, but in contrast with adults eosinophilic inflammation was more likely and neutrophilic inflammation uncommon. ${ }^{8}$ In adults studied during the stable phase, clinical features are similar across the inflammatory phenotypes although sputum eosinophilia appears to predict a greater likelihood of asthma exacerbation ${ }^{9}$ and non-eosinophilic patients may be more likely to be female subjects and non-atopic than the remaining group. ${ }^{2}$ Findings in children differ in that the presence of eosinophilic inflammation appears to predict more severe persistent asthma with impaired lung function and increased AHR. ${ }^{8}{ }^{10}$ Differences in inflammatory phenotypes have also been reported between adults and children presenting with an acute severe 